\title{
Opini Publik dan Kebijakan Pemerintah
}

\author{
Maman Chatamallah
}

\begin{abstract}
A reciprocal relationship exists between public opinion and government policy. Public opinion shaped and reshaped government policies, on the other hand, regulations also influence and transform the public. Public opinion could strengthen support to the administration. On the other hand, weak regulations would create unfavorable public opinion, which in turn will reduce people support toward the government. Such was the case of government policy over energy regulations in Indonesia. Unpopular decision to increase gasoline price made by Megawati administration turned out to be fatal when public opinion swung to another pole. From the image of the party for grass root, PDI then gained popularity as the party who betrayed and corrupted their constituents.
\end{abstract}

Kata kunci: opini public, kebijakan pemerintah, kenaikan BBM

\section{Komunikasi Politik: Birokrasi dan Kebijakan}

Komunikator politik dipandang sebagai orang yang menyampaikan pesan politik kepada khalayak untuk menyampaikan tujuan politik. Pesan yang disampaikan oleh komunikator politik ini berupa informasi. Dalam kegiatan politik, seperti kampanye kandidat dan sosialisasi kebijakan pemerintah, informasi ini adalah produk yang disampaikan. Misalnya, informasi kenaikan harga Bahan Bakar Minyak (BBM) atau informasi pelaksanaan pilkada di Kota Bandung dan kandidatnya. Informasi ini harus melalui proses pematangan agar sebagai produk ia akurat. Informasi ini yang akan mempengaruhi sikap, opini dan pilihan politik khalayak.

Komunikator politik dapat disebut sebagai pihak yang memprakarsai penyampaian pesan kepada pihak lain dalam aktivitas politik. Dalam komunikasi politik, komunikator dapat dibedakan berdasarkan individu-individu, lembaga, atau kumpulan beberapa atau banyak orang (kolektif). Jika seorang tokoh atau pejabat, ataupun rakyat biasa bertindak sebagai sumber dalam suatu kegiatan komunikasi politik, maka dalam beberapa hal ia dapat dilihat sebagai sumber individual (individual source). Pada konteks lain, meskipun seseorang individu yang berbicara, tapi bila ia menjurubicarai suatu lembaga atau organisasi, maka pada saat itu dapat dipandang sebagai collective source atau sumber kolektif. Pembedaan antara komunikator individual dan yang kolektif dalam proses komunikasi politik dapat digambarkan sebagaimana pada gambar 1 .

Sumber individual saling berkaitan dengan sumber kolektif. Para pejabat birokrat sebagai sumber individual, tentunya, berada di bawah suatu pelaksanaan dan pengawasan pemerintah atau birokrasi. Pada tingkat pemerintah tersebut 


\section{Gambar 1}

\section{Sum ber (Kom unikator) Individual dan Kolektif dalam Komunikasi Politik}

\begin{tabular}{ll}
\hline Individual & Kolektor \\
\hline Pejabat (birokrat) & Pemerintah (birokrasi) \\
Politisi & Partai Politik \\
Pemimpin Opini & Organisasi kemasyarakatan \\
Jurnalis & Media massa \\
Aktivis & Kelompok penekan \\
Lobbyist & Kelompok elit \\
Pemimpin & Badan/perusahaan komuniksai \\
Komunikator Profesional & \\
\hline
\end{tabular}

kebijakan direncanakan dan diputuskan untuk dilaksanakan. Tentang mereka yang berkedudukan sebagai birokrat, Katz dan Kahn (1966) mengemukakan,

"Seorang birokrat adalah anggota suatu birokrasi yang merupakan suatu organisasi dengan tugas melaksanakan suatu kebijaksanaan (policy) yang ditentukan oleh pembuat kebijaksanaan (policy makers)."

Seorang birokrat hanya dapat bekerja dalam bidang yang sudah ada aturannya. Apabila ada sesuatu hal yang belum ada peraturannya sebagai dasar pelaksanaannya maka seorang birokrat tidak merasa dirinya kompeten untuk melaksanakannya.

Almond dan Powell (1963) menggambarkan birokrasi pemerintah sebagai suatu kelompok yang terdiri dari para petugas dan jabatan yang dipertautkan melalui hirarki yang terperinci, dan tunduk kepada pembuat aturan formal. Birokrasi ditandai dengan adanya spesialisasi tugas, tanggung jawab, dengan aturan-aturan/prosedur yang formal dan standar. Karena itu, dalam kedudukannya sebagai komunikator, para birokrat merupakan orang-orang yang mempunyai kemampuan secara teknis dalam bidangnya dan memiliki informasi yang bersifat esensial untuk pembuatan dan penegakan kebijakan publik.

Birokrat dan birokrasi memiliki kewajiban untuk mendukung suatu kebijakan yang telah diputuskan pemerintah dan menyebarluaskannya kepada khalayak. Misalnya, kebijakan tentang kenaikan tarif listrik, telepon, dan BBM. Kebijakan tersebut merupakan keputusan para pejabat pada tingkat eksekutif, setelah melalui persetujuan legislatif. Kebijakan tersebut dikomunikasikan kepada rakyat secara luas oleh pejabat di birokrasi. Kebijakan kenaikan harga itu disetujui, saat itu, oleh Presiden Megawati dan diumumkan oleh pembantu presiden, yakni para menteri yang terkait. Kebijakan yang diputuskan dan disosialisasikan kepada masyarakat itulah informasi sebagai produk.

Informasi yang disampaikan pemerintah kepada masyarakat, dan sebaliknya dari masyarakat kepada pemerintah dapat menghasilkan pemahaman di antara kedua belah pihak. Menurut Nasution (1889), rakyat membutuhkan informasi mengenai apa yang dilakukan pemerintah untuk mereka, dan pemerintah membutuhkan informasi mengenai apa yang rakyat inginkan dan harapkan dari pemerintah. Oleh karenanya, pemerintah membutuhkan kritik dan masukan dari rakyat. Menurut Alfian, di sinilah komunikasi politik bekerja seperti sebuah sirkulasi darah. Yang dibutuhkan oleh tubuh adalah (1) sirkulasi darah yang mengalir tanpa hambatan, dan (2) nutrisi yang terkandung dalam darah. Jadi, tidak boleh ada hambatan dalam demokratisasi, seperti pembungkaman oleh pemerintah, pem-breidel-an pers, atau ancaman, dan rakyat harus berkomunikasi dengan pemerintah dengan cara 
yang santun. Lalu, yang tidak kalah pentingnya, isi informasi dari kedua belah pihak harus benar, akurat, dan berkualitas, bukan atas dasar asumsi atau prasangka-prasangka.

\section{Demokrasi dan Partai Politik}

Menurut Denny J.A., di seluruh dunia, tidak ada negara demokrasi yang sehat hidup dengan ratusan partai politik. Di Amerika Serikat, bahkan hanya hidup dua partai politik. Di Eropa Barat dan di wilayah lain di mana sistem multi-partai subur, tetap saja hanya ada tiga sampai lima partai yang hidup. Bagi negara demokrasi yang stabil dan plural mempunyai enam partai politik besar seperti di Indonesia saja sudah terlalu banyak. Alam demokrasi tidak menggunakan larangan secara langsung bagi pendirian partai politik. Pembatasan partai politik dilakukan dengan menerapkan berbagai prosedur sistem pemilu. Secara sah, legal, dan demokratis, sistem pemilu menjadi alat rekayasa yang dapat menyeleksi dan memperkecil jumlah partai politik dalam jangka panjang.

Untuk memperketat jumlah partai, dapat dilakukan pemilu dengan sistem distrik atau proporsional. Sistem distrik cenderung membuat partai politik hanya menjadi dua saja. Dalam sistem distrik, teritori sebuah negara dibagi menjadi sejumlah distrik. Banyaknya jumlah distrik itu sebanyak jumlah anggota parlemen yang akan dipilih. Setiap distrik akan dipilih satu wakil rakyat.

Dalam sistem distrik, berlaku prinsip the winner takes all. Partai minoritas tidak akan pernah mendapatkan wakilnya. Misal, dalam sebuah distrik ada sepuluh partai yang ikut serta. Tokoh partai A hanya menang 25 persen, namun tokoh partai lain memperoleh suara yang lebih kecil. Walau hanya mendapatkan 25 persen suara, distrik itu akan direbut oleh sang tokoh. Sembilan tokoh lain, yapg perolehan suaranya Iebih kecil akan tersingkir.

Metode the winner takes all ini menjadi insentif negatif bagi partai kecil. Dalam studi perbandingan, sistem distrik ini memang merangsang partai kecil untuk membubarkan diri atau menggabungkan diri dengan partai lain, agar menjadi mayoritas. Dalam perjalanan waktu, sistem ini hanya menyisakan dua partai besar saja. Partai kecil lainnya terkubur dengan sendirinya.

Sementara sistem proporsional memiliki mekanisme sendiri. Berbeda dengan sistem distrik, sistem proporsional memungkinkan partai kecil dan partai minoritas untuk mempunyai wakil di DPR. Di sebuah provinsi, misalnya, partai yang hanya dapat 1 persen suara sangat mungkin mendapatkan kursi jika dalam provinsi itu dibagikan lebih dan seratus kursi parlemen. Namun, sistem proporsional menerapkan electoral threshold. Ada batas minimal persentase yang harus dimiliki partai untuk dapat aktif di parlemen. Di Indonesia, misalnya, ditetapkan threshold 2\% suara pada Pemilu1999 dan 5\% pada Pemilu 2004. Partai yang tidak mencapai kursi DPR sebanyak ketentuan electoral treshold tidak mempunyai fraksi. Itu sebabnya Partai Keadilan tidak memiliki fraksi dan bergabung dengan fraksi PAN menjadi Fraksi Reformasi pasca pemilu 1999. Lebih dari itu, partai yang tidak lolos threshold dilarang pula ikut Pemilu selanjutnya. Melalui aturan threshold, pada Pemilu 1999, Indonesia hanya memiliki enam partai saja: PDIP, Golkar, PPP, PKB, PAN, dan PBB. Pada Pemilu 2004, peta politik berubah. Muncul tujuh partai besar yang lolos threshold, yakni Golkar, PDIP, PKB, PPP, PKS, Partai Demokrat dan PAN.

Aturan threshold di Indonesia tergolong sangat lunak. Di Turki, misalnya, persentase threshold itu adalah 10 persen. Partai yang tidak mencapai threshold 10 persen tidak akan punya fraksi di panlemen. Lebih dari itu, threshold j uga diberlakukan secara lebih keras. Partai yang tidak dapat suara 10 persen tidak diizinkan punya wakil di parlemen. Suara perolehan partai itu dinyatakan hangus, dan diambil alih oleh partai lain yang lolos. Melalui threshold ini, partai kecil kembali terkubur secara demokratis. Melihat perbandingan dengan dunia lain, terkuburnya ratusan partai kecil dan partai baru adalah pemandangan yang lazim. Jika memang menginginkan demokrasi yang stabil, sebagaimana layaknya demokrasi di dunia maju, memang tidak boleh ada banyak partai politik. Dua partai cukup. Atau, jika multipartai, empat sampai lima partai sudah cukup. Seleksi dilakukan melalui sistem pemilu yang ketat. Seleksi itu sah adanya dan demokratis 


\section{Gambar 1 \\ The State/Goverment/Political establisment}

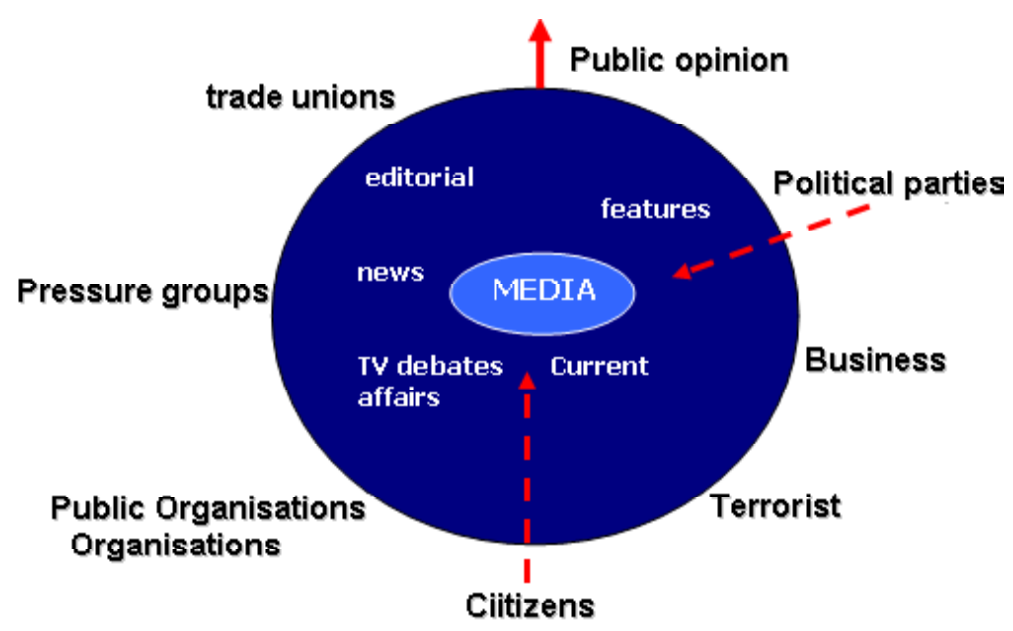

Biasanya ada kecenderungan partai-partai besar melakukan: "kerjasama" bahkan "perselingkuhan" dengan media massa. Ini dilakukan untuk meraih pembaca, penonton, dan perndengar media sebagai khalayak komunikasi politik. Logika media ditentukan oleh keuntungan yang diperoleh media sebagai industri; dan logika politik ditentukan oleh kepentingan untuk mencapai kekuasaan. Keduanya akan melakukan "perselingkuhan" bila keuntungan media dan kepentingan politik terpenuhi. Makanya, tidaklah heran, media dapat menjadi alat politik pihak tertentu dari penguasa atau mereka yang ingin berkuasa. Kadang tidak terlihat, namun bila diamati dengan berbagai pendekatan penelitian, analisis isi teks media dan tayangan berita, analisis wacana dan framing, hal itu dapat terlihat (dalam Ibnu Hamad, 2004).

\section{Opini Publik dan Pengambilan Keputusan}

Berkaitan dengan makalah yang telah dibuat, saya contohkan agar lebih jelas. Dalam makalah saya mengutip pendapat Habermas yang

menyatakan konsep public sphere (ruang publik). Hal ini digambarkan oleh McNair (2000) yang menyatakan bahwa public sphere membuka ruang bagi publik atau khalayak politik untuk memengaruhi kebijakan pemerintah. Memang ada pula pengaruh lain, seperti organisasi bisnis dan perdagangan, partai politik, kelompok penekan, dan lainnya. Semuanya akan mengkristal dalam berbagai macam opini publik memengaruhi pemerintah.

Sebagai contoh, disadari atau tidak munculnya keputusan Mahkamah Konstitusi yang membuka peluang calon independen, nonpartai politik, mengikuti pilkada, juga dipengaruhi oleh wacana dan opini publik yang berkembang di masyarakat tentang hal itu. (Sumber: McNair, 1999)

Dalam politik, dikenal suatu konsep yang disebut sistem politik. Dalam konsep ini, ditemukan adanya istilah-istilah seperti proses, struktur, dan fungsi. Proses adalah pola-pola (sosial dan politik) yang dibuat oleh manusia dalam mengatur hubungan antara satu sama lain. Dalam suatu negara, lembaga-lembaga seperti parlemen, partai, birokrasi, sekalipun sudah mempunyai kehidupan 
sendiri, sebenarnya tak lain dari proses-proses yang pola-pola ulangannya mantap.

Sistem politik juga menjalankan fungsi-fungsi tertentu untuk masyarakat. Fungsi-fungsi itu adalah membuat keputusan-keputusan kebijaksanaan (policy decision) yang mengikat dari alokasi nilai-nilai (baik yang bersifat materiil, maupun nonmateriil) Keputusan-keputusan kebijaksanaan ini diarahkan kepada tercapainya tujuan-tujuan masyarakat. Sistem politik menghasilkan "output" yaitu keputusankeputusan kebijaksanaan yang mengikat. Dengan kata lain: melalui sistem politik, tujuan-tujuan masyarakat dirumuskan dan selanjutnya dilaksanakan oleh keputusan-keputusan kebijaksanaan (Budiardjo, 1998:48).

Opini publik yang diperhitungkan dalam pembuatan kebijakan, menurut Hennesy (1970) adalah suatu kompleksitas dari pandanganpandangan, kelompok, dan individual yang seyogyanya dapat disebut sebagai opini publik, atau opini yang dianut oleh para anggota publik. Opini ini berperan dalam pembuatan keputusan dalam bentuk berbagai cara dan dalam kombinasi berbagai suara untuk memengaruhi kebijakan yang dinyatakan, yang merupakan keseimbangan (equilibrium) yang tercapai pada perjuangan kelompok pada saat tertentu.

Para pembuat keputusan, terutama legislator dan administrator, memiliki suatu ukuran yang

Gambar 2

Model Proses antara Opini Publik dengan Kebijakan

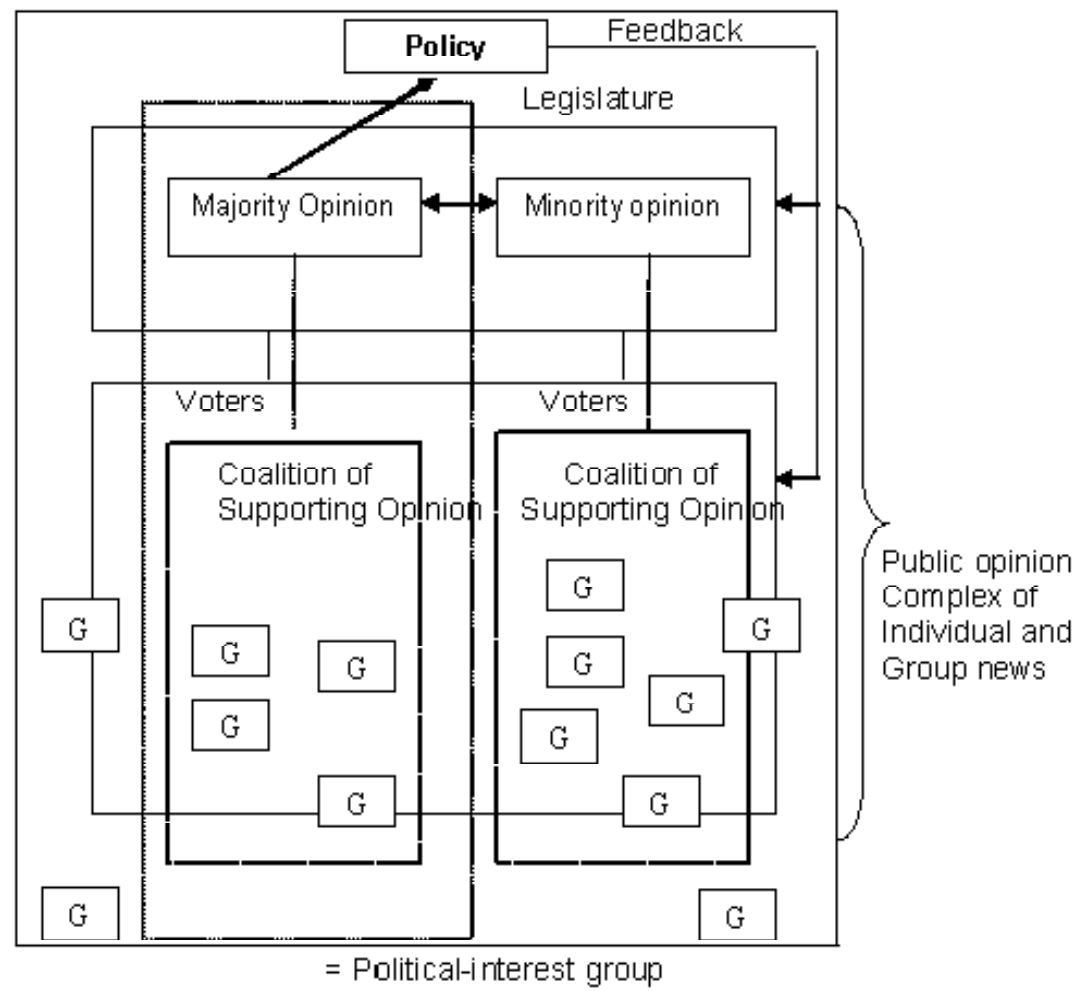

(Repro: Hennesy, 1970) 


\section{Gambar 3}

\section{Kebijakan BBM di Setiap Rezim}

\section{Kebijakan BBM di Setiap Rezim}

Yenaikan harga bahan bakar mimyak |(68M)| Anamgir dllakukan oleh setsap rezim sant memimpin pemerintahan. Umumnya, wenak. an harge tersehut tak berlangsung mulus. Selalu ada penolakan, baik dari mahasiswa: masyarakat hingsa pardemen. Risiko politik. nya pun tidak hocil. Kenalkan harga BBM of mass Presiden Scehtrto memicu aksi demo

\section{PRESIDEN SOEHARTO}

- Harga BeM dinaikkan 25-71,43 per. sen pada Me: 1998

- Aksi messa dan mahasiswa meluas til berbagai daerah dan sedure DPR dikustai

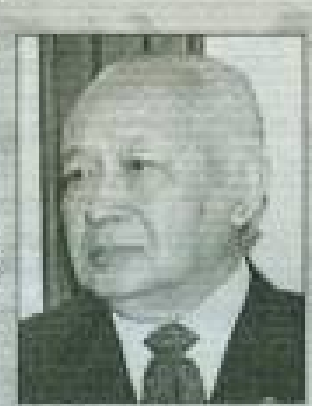

- Paelemen yang dilowasai Gölkar akhimys mendulung aksi mahasiswa

- Souhra do djatuhkan dari kursi plesiden

\section{PRESIDEN MEQAWATI SOEKARNOPUTRI}

- Harga BeM dinaikkar bersamain de: ngan taris listrick can teiepon 1 . A ntiaxt 2003

- Akrsi mássa dia mahasisws meluas di beibagai daerch

× Kutu DPR pendo-

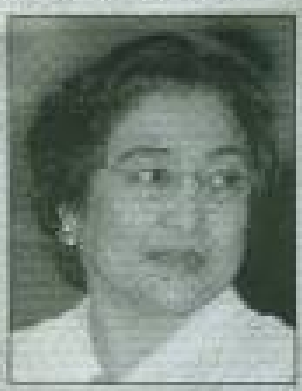
lung kendikan harga BBM: PDr Perjuanden dan Ppp

- Kubu DPR penolak kenalken harga B日M: Kaukas Penyelamat Bangsa fFraksi Refor(mesil. Golkar, den PKB)

- Penolakan DPR menguat sehingga Nega wati merevisk kenalkan heroa BBM besar-besaran hingsa menjatuhtan dirinya dari kursi kakuesaannya pada 1998. Begitu pula, saat KR Abuturabman Wakid meminpin pemerintahan, kenaikan harga BBM menjadi salah satu alasan DPR, selain kasus Bu togate untuk mengadaken Sidane istimewa pado zoll 2002 yang bertjung usda jatunima Abdurramesi Wahid dari kursi presiden.

\section{PRESIDEN ABOURRAHMAN WAHID}

- Harga BBM nak 10 stober 2000

- Aksi massa dan mahasiswa terjedi di berbegai daerah

- Kutu DPR pendur. lung kanaikas ha Ea BBM: PKB

- Kutcu DPR ponolabs

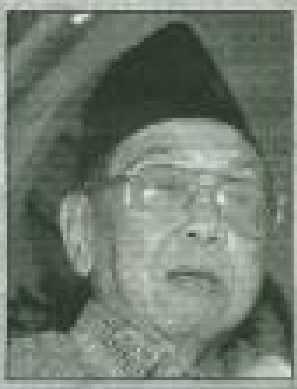
henaikan harga BEM: PDIP, Refomasi, PPP, dan Golkar

- Presican jath kerena buicelsate Quga BBM).

\section{PRESIDEN SUSILO BAMBANG YUDHOYONO}

a Haga B日M dinaik. ican pada 1 Maret 2005

- Alcsi massa dan mahasiswa terad. di berbagal daerah

- Kubu DPR pendu kung kenaikan har: ge BBM: Eotkar;

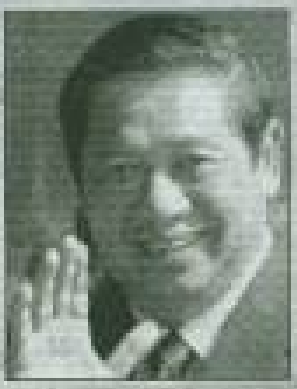
Demokrat, PKS, PPp

- KuJu DPR penolak kenaikan harga B8M. PDI Perjuangan, PKB, PAN, PBR, dan PDS

- DPR mengancanr akan melałoukan Sidang. Peripuma.

heritan betbajas sumbut 
fleksibelitas yang besar karena countervailing power dapat diberlakukan antara satu sama lainnya. Pada saat yang sama, semua warga negara yang terorganisasi dalam sejumlah kelompok penekan mampu memanfaatkan rivalitas yang berlangsung diantara kelompok pemimpin yang bersaing.

Contoh yang paling mudah dalam konteks ini adalah kebijakan yang selalu menuai kritik publik, yakni kenaikan Bahan BakarMinyak (BBM). Siapa pun pemegang kekuasaan di tanah air, tak dapat mengelakkan diri dari kebijakan tersebut. Dari Soeharto sampai Yudhoyono melakukan "penyesuaian" harga BBM. Dibuat dan diputuskannya kebijakan kenaikan harga BBM oleh pemerintah, pada dasarnya, untuk mengeluarkan negara Indonesia dari krisis ekonomi. Namun, kebijakan presiden yang tidak "populer" tersebut mendapatkan tanggapan negatif dari masyarakat bahkan tokoh-tokoh ekonomi dan politik.

Berdasarkan pendapat Hennesy, opini publik memiliki peranan dalam pembuatan kebijaksanaan. Namun, dalam kebijakan kenaikan harga BBM yang ditentang oleh masyarakat, dengan tanggapan negatif terhadap kebijakan tersebut, pemerintah tidak membuat kebijakan baru sesuai keinginan rakyat. Pemerintah tidak mempertahankan harga BBM. Pemerintah tetap mencabut subsidi atas BBM sebagai kebijakan dalam menanggapi opini negatif masyarakat terhadap kebijakan sebelumnya. Meski menjadi mayoritas, ketidakpuasan masyarakat, kelompok kepentingan dan kelompok penekan seperti mahasiswa terhadap keputusan tersebut, belum tentu dapat mengubah kebijakan pemerintah.

Sementara itu, partai utama penguasa di DPR sudah pasti mendukung kebijakan pemerintah menaikkan BBM. Pada pemerintahan Abdurrahman Wahid, PKB mendukung kenaikan harga BBM, lalu PDI-Perjuangan dan PPP mendukung penuh kenaikan BBM saat Megawati menjadi Presiden (lihat Gambar 3). Seperti biasa, partai yang tidak mendapat "kue" kekuasaan tentu saja menentang kebijakan itu, bahkan tampak mati-matian. Sebut saja PDI-Perjuangan yang menolak kebijakan BBM pemerintah Susilo Bambang Yudhoyono. Langkah PDI-P ini ternyata tidak substansial karena ternyata mereka bukan menolak kenaikan harga BBM, tetapi proses pengambilan kebijakan tentang BBM yang tidak melalui persetujuan DPR. Padahal, perhatian utama masyarakat pada kenaikan harga BBM yang dirasa memberatkan.

Yang dikhawatirkan, kini masyarakat menjadi imun. Pertama, masyarakat tidak lagi peka terhadap kebijakan pemerintah yang berpaling dari kepentingan rakyat seperti menaikkan BBM. Masyarakat merasa lelah mengkritisi kebijakan pemerintah. Semakin lama, ini dapat menimbulkan ketidakpekaan, karena mereka bicara pun kebijakan tidak berubah. Saking lelahnya mereka bisa apatis terhadap sistem politik yang ada. Bisa saja muncul pernyataan, " $A h$, sejak dulu kita enggak mau harga BBM naik, tapi pemerintah cuek aja. Yah, kita keberatan juga tetep aja enggak ada yang berubah. Ya udah, biarin aja". Kedua, masyarakat tidak lagi memercayai partai politik karena perilakunya selama ini tidak merepresentasikan kepentingan konstituen dan publik yang lebih luas. Inilah yang dialami PDI-P yang dianggap bukan lagi partai wong cilik karena PDI-P sama saja dengan partai lain yang menaikkan harga BBM. Ini membuat positioning PDI-P pada Pemilu 1999 dan 2004 telah berubah. Menurut Denny J.A. (2006c), persepsi publik terhadap PDI-P sebagi partai wong cilik berubah menjadi partai paling korup.

\section{Daftar Pustaka}

Denny J.A. 2006a. Memperkuat Pilar Kelima. Jakarta: LKIS.

2006b. Politikyang Mencari Bentuk. Jakarta: LKIS

2006c. Partai Politik pun Berguguran, Jakarta. LKIS.

McNair, Brian. 1999. Introduction to Political Communication. London: Routledge.

Nasution, Zulkarimen. 1990. Komunikasi Politik Suatu Pengantar. Jakarta: Ghalia Indonesia. 
